\title{
Autologous Dendritic Cells Pulsed with MART-1 (26-35) Peptide
}

National Cancer Institute

\section{Source}

National Cancer Institute. Autologous Dendritic Cells Pulsed with MART-1 (26-35)

Peptide. NCI Thesaurus. Code C142814.

A cell-based vaccine consisting of autologous HLA-A2*0201-restricted dendritic cells (DC), which were derived from patient-harvested adherent peripheral blood monocytes cultured in vitro with granulocyte-macrophage colony-stimulating factor (GM-CSF) and interleukin-4 (IL-4), that were pulsed with a peptide fragment comprised of amino acid residues 26 through 35 of melanoma antigen recognized by T-cells 1 (MART -1 (26-35)), with potential immunostimulatory and antineoplastic activities. Upon intradermal vaccination, autologous DC pulsed with MART-1 (26-35) peptide may stimulate the host immune system to mount a cytotoxic T-lymphocyte immune response against tumor cells expressing MART -1. MART-1, a protein involved in melanosome biogenesis, is overexpressed by melanoma cells. The MART -1 (26-35) peptide is highly immunogenic for the HLA-A2*0201 haplotype. 